Article

\title{
Establishing a System for Testing Replication Inhibition of the Vibrio cholerae Secondary Chromosome in Escherichia coli
}

\author{
Nadine Schallopp ${ }^{1,+}$, Sarah Milbredt ${ }^{1,+}$, Theodor Sperlea ${ }^{1,+}{ }^{+}$Franziska S. Kemter ${ }^{1,+}$, \\ Matthias Bruhn ${ }^{1}$, Daniel Schindler ${ }^{1,2}$ and Torsten Waldminghaus ${ }^{1, *}$ \\ 1 LOEWE Center for Synthetic Microbiology-SYNMIKRO, Philipps-Universität Marburg, Marburg 35032, \\ Germany; nadine@schallopp.de (N.S.); Sarah.Milbredt@ruhr-uni-bochum.de (S.M.); \\ theodor.sperlea@staff.Uni-Marburg.DE (T.P.); Kemter@students.uni-marburg.de (F.S.K.); \\ bruhnmatthias@aol.com (M.B.); daniel.schindler@manchester.ac.uk (D.S.) \\ 2 School of Chemistry, Manchester Institute of Biotechnology, University of Manchester, \\ Manchester M1 7DN, UK \\ * Correspondence: torsten.waldminghaus@synmikro.uni-marburg.de; Tel.: +49-6421-282-3338 \\ $+\quad$ N.S., S.M., T.S. and F.S.K. contributed equally to this work.
}

Academic Editor: Anders Løbner-Olesen

Received: 30 October 2017; Accepted: 20 December 2017; Published: 23 December 2017

\begin{abstract}
Regulators of DNA replication in bacteria are an attractive target for new antibiotics, as not only is replication essential for cell viability, but its underlying mechanisms also differ from those operating in eukaryotes. The genetic information of most bacteria is encoded on a single chromosome, but about $10 \%$ of species carry a split genome spanning multiple chromosomes. The best studied bacterium in this context is the human pathogen Vibrio cholerae, with a primary chromosome (Chr1) of $3 \mathrm{M} \mathrm{bps}$, and a secondary one (Chr2) of about $1 \mathrm{M}$ bps. Replication of Chr2 is under control of a unique mechanism, presenting a potential target in the development of $V$. cholerae-specific antibiotics. A common challenge in such endeavors is whether the effects of candidate chemicals can be focused on specific mechanisms, such as DNA replication. To test the specificity of antimicrobial substances independent of other features of the $V$. cholerae cell for the replication mechanism of the $V$. cholerae secondary chromosome, we establish the replication machinery in the heterologous $E$. coli system. We characterize an E. coli strain in which chromosomal replication is driven by the replication origin of $V$. cholerae Chr2. Surprisingly, the E. coli ori2 strain was not inhibited by vibrepin, previously found to inhibit ori2-based replication.
\end{abstract}

Keywords: chromosome engineering; replication initiation; drug development

\section{Introduction}

While the genetic setup in eukaryotic cells comprises multiple linear chromosomes, the standard in prokaryotes is a single circular chromosome [1]. The number of replication start sites is also different, with eukaryotic chromosomes starting replication at multiple origins, while all known bacterial chromosomes are replicated from a single origin of replication. However, in bacteria, some interesting exceptions occur in alternative genetic setups, including linear chromosomes and separation of the genetic information onto multiple chromosomes [2,3]. When two chromosomes exist in one bacterial cell, new questions arise about, for example, the timing of initiation and coordination of segregation in comparison to single-chromosome bacteria. The best studied two-chromosome bacterium is Vibrio cholerae, the causative agent of the cholera disease [4,5]. Chr1 of V. cholerae strain El Tor N16961 has a size of about $3 \mathrm{M}$ bps and Chr2 of about $1 \mathrm{M}$ bps [6]. Each of the two chromosomes has its own initiator protein to start replication at each single replication origin [7]; for Chr1, the initiator is 
DnaA, known to be the standard from studies in other model bacteria [8]. Meanwhile, the initiator for $\mathrm{Chr} 2$ is the protein RctB $[8,9]$. Although RctB is unique within the phylogenetic group of Vibrionaceae, it shows structural similarity to plasmid initiators $[10,11]$. This fits the common idea that Chr2 originates from a plasmid that was acquired by the cell early in evolution and then developed into a secondary chromosome [12]. One chromosome-like characteristic of Chr2 is its regulation in a cell-cycle dependent manner, attributed to the participation of SeqA and Dam methyltransferase in regulation of ori2 [13-15]. Another feature of Chr2, further distinguishing it from plasmids, is that it encodes essential genes, although they are less frequent than when compared to the primary chromosome [16,17]. However, the plasmid ancestry of $\mathrm{Chr} 2$ is shown by the similarity of its replication initiation mechanism to plasmid systems; one such shared feature of both is the binding of the initiator protein to an array of specific binding sites, the so-called iterons [18]. In addition, handcuffing is involved in negative regulation of ori2 as has also been shown for plasmid origins [12]. Although RctB alone is sufficient to melt the DNA double strand at ori2, this replication origin has been found to also depend on DnaA [8], the experimental evidence being the inability of the transfer of an ori2-based minichromosome to an E. coli strain lacking DnaA [5]. DnaA activity at ori2 is probably linked to a conserved DnaA box some base pairs away from the iteron array [6,19]. Coordination of replication in the two-chromosome system of $V$. cholerae appears to work through the crtS site (=chromosome II replication triggering site), located on $\mathrm{Chr} 1$ and found to positively regulate initiation at ori2 by binding RctB [20]. Regulation is thought to include physical contacts between $c r t S$ and ori2, as these two chromosome parts appeared to be coupled in chromatin conformation capture experiments [21]. Genetic changes of the crtS position on Chr1, either closer to ori1 or further away, resulted in a corresponding shift of Chr2 initiation time as seen by a changed copy number [21], showing that the native position of the $\mathrm{crtS}$ sets the timing of $\mathrm{Chr} 2$ replication to finish in synchrony with Chr1 replication [21-23]. An important tool in studies on V. cholerae DNA replication was and is the use of E. coli as a heterologous host. First evidence of which sequences function as replication origins in $V$. cholerae came from testing their ability to replicate a corresponding minichromosome in E. coli [5]. Later, the native replication origin of E. coli was replaced by the very similar ori1 of the primary $V$. cholerae chromosome $[13,14]$, which was used to show that the Dam methyltransferase is not essential for ori1 replication and can thus not be responsible for Dam being essential in $V$. cholerae (and not in E. coli). The conclusion was therefore that Dam-dependent methylation of ori2 is crucial for initiation of replication; this assumption was confirmed by showing firstly that RctB binding sites need to be methylated in order to be bound by RctB, and secondly, that Dam loss selects for chromosome fusion in $V$. cholerae, omitting the need for a functional ori2 since all genetic material can be replicated by ori1 $[13,24]$. Attempts to construct an E. coli strain with $V$. cholerae ori2 driving DNA replication instead of oriC as an important tool to study related questions had previously been unsuccessful [13]. Here, we study replication of such a strain with an insertion of ori2 including the genes encoding par $A B$ and $r c t B$ at position 4,422,941 of the E. coli chromosome and an oriC deletion that was constructed on the way toward developing an E. coli strain with two chromosomes [25]. We show that chromosomes over-replicate in E. coli with an ori2 origin and that its replication is indeed dependent on Dam. Further experiments assess the relationship of $c r t S$ to ori 2 copy number, the role of DnaA in ori2 initiation and make use of the genetic system to study a chemical compound that was described to act specifically on RctB. Finally, we show that ori2 can replace oriC at its native location by constructing a corresponding strain.

\section{Results}

\subsection{Cholerae ori2 Dependent Replication of the E. coli Chromosome}

In order to establish a test system for replication inhibitors of $V$. cholerae ori2 we analyzed an E. coli strain which has this origin including the flanking genes $r c t B$ and par $A B$ inserted at an ectopic site and the native oriC being deleted (strain \#16) [25]. Exponentially growing cultures were treated 
with rifampicin, which blocks replication initiation, and cephalexin, which inhibits cell division [26]. In wildtype E. coli (wt) cells, this treatment led to cells containing either 4 or 8 fully replicated chromosomes (Figure 1A). However, the flow cytometry histogram of a strain in which chromosomal replication is driven solely by ori2 (strain \#16) looks completely different (Figure 1A). Total DNA content in the strain driven by ori2 is higher on average than when compared to the wt strain, and no distinct peaks are visible indicating unfinished replication rounds. Our analysis fits a chromosome replicated by ori2 in this strain, as ori2 was shown to be insensitive to rifampicin treatment in comparison to oriC in E. coli and ori1 in V. cholerae [22,23]. Clearly, a different experimental approach is needed to assess if ori2-driven replication in E. coli has similar timing to oriC-based replication, or if initiation timing is different and/or potentially disturbed. To answer this question, we used quantitative fluorescence microscopy based on a recently constructed FROS array inserted into the lacZ locus [27] (Figure 1B,C). Since the FROS array marks one region of the chromosome, the number of respective foci should correlate with chromosome copy numbers. In exponentially growing cells of the ori2-strain (SM113), we could detect a clear increase in the number of foci compared to the control strain with oriC (SM112) (Figure 1B,C). This observation suggests that the ori2-based chromosome in E. coli over-initiates, in comparison to the native oriC-driven replication. To verify this finding, we performed microarray-based comparative genomic hybridization (CGH) to examine genome wide gene copy number patterns (Figure 1D). Over-initiation should lead to an increased origin to terminus copy number [28]; indeed, the strain with ori2 had an origin copy number of 3.2, which is significantly more than the wt strain under similar growth conditions (Compare red and blue line in Figure 1D). These results indicate that replication of the primary E. coli chromosome by ori2 increases the number of initiation events within one cell cycle in comparison to wt $E$. coli. The CGH experiments also confirmed ori2 to be the only active replication origin in the analyzed strain because the copy number maximum appeared at the chromosomal position of ori2 insertion (Figure 1D).

A

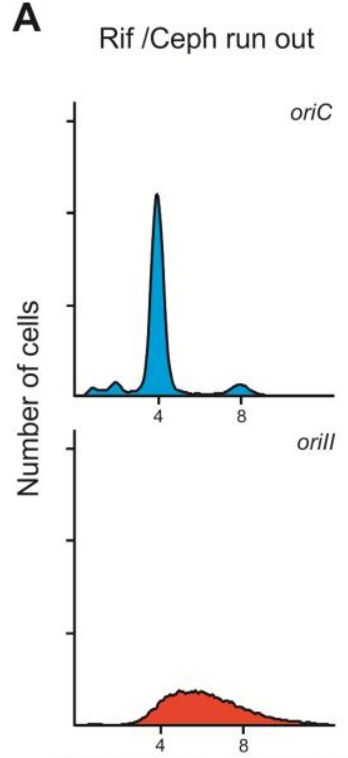

chromosome equivalents
B

B TetR-mVenus
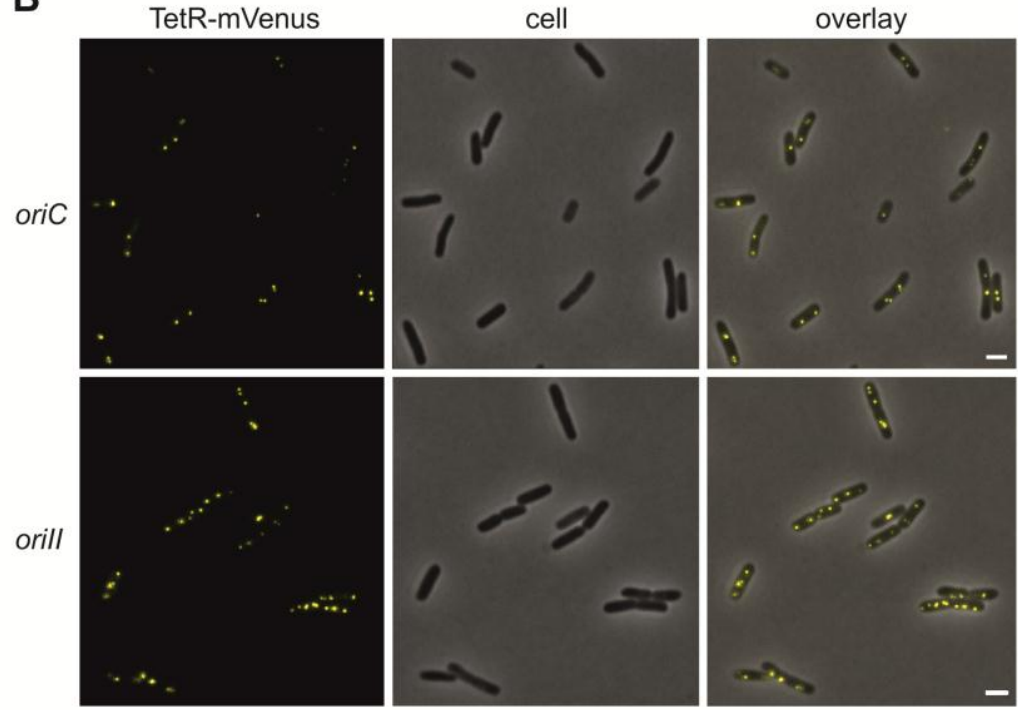

Figure 1. Cont. 
C

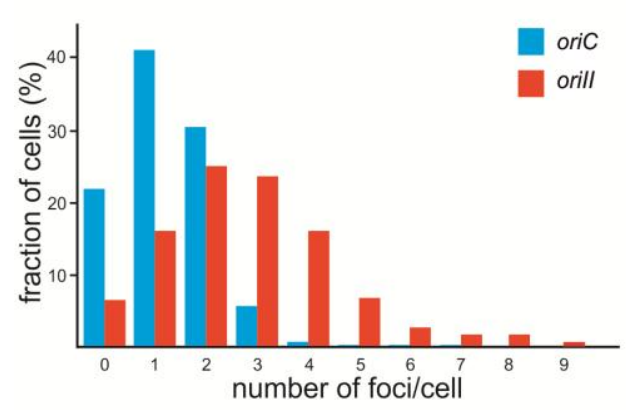

D

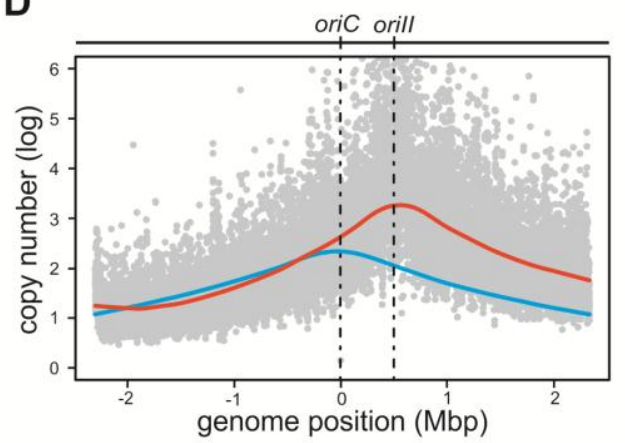

Figure 1. DNA replication in E. coli strains with oriC or ori2 driven replication. (A) Flow cytometry analyses of DNA content in rifampicin/cephalexin treated $E$. coli cells with DNA replication starting at oriC (strain \#1; top panel) or V. cholerae ori2 (strain \#16; bottom panel) [25]. (B) Fluorescence microscopy of E. coli cells harboring a plasmid encoding a TetR-mVenus fusion (pMA289), a FROS array insertion and either oriC (top panel; strain SM112) or ori2 (bottom panel; strain SM113). The scale bar is $2 \mu \mathrm{m}$. (C) Quantification of fluorescence foci per cell for microscopy shown in B ( $n=700)$. (D) Profile of genome-wide copy numbers based on comparative genomic hybridization (CGH). Grey dots represent values of single probes for the ori2-based strain (\#16) with a Loess regression (red line, $\mathrm{F}=0.2$ ). For comparison, the Loess regression of the oriC-based strain \#1 is shown based on published data [29] (blue line, $\mathrm{F}=0.2$ ). Positions of oriC and ori2 are indicated and the genomic position as distance from oriC.

\subsection{Initiation of Replication at ori2 in E. coli Depends on Dam Methylation}

Dam methyltransferase was shown to be essential in V. cholerae [30]. An E. coli strain with oriC substituted by $V$. cholerae ori1 was instrumental to show that this is due to effects of Dam on ori2 and not ori1, as Dam was not essential in this strain [13,14]. Therefore, one conclusion would be that Dam should be essential in an E. coli strain with ori2 driving chromosomal replication. To test this hypothesis, we analyzed the transfer of a $\Delta$ dam allele by P1 transduction to an E. coli strain in which replication is solely driven by ori2 (\#16). While the deletion could easily be introduced to E. coli wt cells, no transduction was found in strain \#16 (Figure 2). In contrast, the positive control hupA, encoding one subunit of the DNA-binding protein $\mathrm{HU}$, could be transduced into both strains with similar efficiencies (Figure 2). The same was observed for an antibiotic cassette insertion within the seqA locus. This result confirmed previous findings of SeqA not being essential for ori2-dependent initiation of DNA replication.

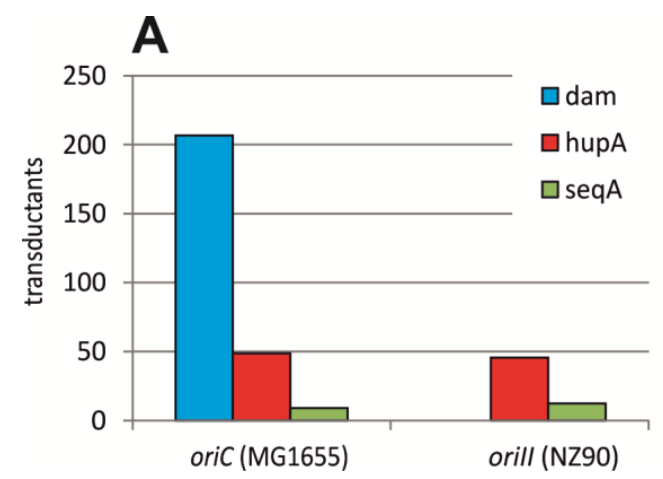

\section{B}

\begin{tabular}{|l|l|r|r|}
\hline Strain & Allele & Transductants & Stand. dev. \\
\hline MG1655 & dam & 207 & 90 \\
\hline & hupA & 49 & 26 \\
\hline & seqA & 9 & 8 \\
\hline NZ90 & dam & 0 & 0 \\
\hline & hupA & 46 & 28 \\
\hline & seqA & 12 & 3 \\
\hline
\end{tabular}

Figure 2. Transduction efficiency of gene knockouts into oriC and ori2 E. coli strains. Colonies growing on plates supplemented with kanamycin were counted after P1 transduction of KanR-cassettes inserted in dam, hapA or seqA as indicated into E. coli strains, with chromosome replication based on oriC (MG1655 (\#1)) or ori2 (NZ90). Mean values of three replicates are shown in (A) with the actual numbers and standard deviation given in the table (B). 


\section{3. crtS-Dependent Regulation of ori2-Based Replication in E. coli}

$V$. cholerae Chr1 was found to encode a short DNA sequence called crtS (chromosome II replication triggering site) that regulates initiation at ori2 [20,21]. We hypothesized that the ori2-driven chromosome in strain \#16 is dysregulated due to lacking a crtS site. The $c r t S$ site was found to increase the copy number of an ori2-minichromosome in E. coli [20]. However, in those experiments, crtS was supplied in multiple copies through a pBR322 plasmid, which is unlike the situation in $V$. cholerae. To analyze the effect of more physiological numbers of $c r t S$ on ori2 replication, we inserted a crtS site on the E. coli wt chromosome driven by oriC between genes fucR and $r l m M$ (genomic position $\sim 2,940,120$ ) about $1 \mathrm{M}$ bps from oriC. The strain was transformed with an ori2-minichromosome and its copy number determined via quantification of the sensitivity towards elevated concentrations of antibiotics, the underlying logic being that higher replicon numbers lead to higher gene dosage of the encoded resistance gene and correspondingly to a higher tolerance towards respective antibiotics [31-33]. An increased copy number of the ori2-minichromosome was observed in a strain carrying the $\mathrm{crtS}$ insertion, compared to the wt lacking crtS (Figure 3A). Notably, this effect was ori2 specific, since a replicon driven by the F-plasmid replication origin did not show differential copy numbers (Figure 3A). To verify these results, we measured ori2-minichromosome copy numbers relative to the primary E. coli chromosome by qPCR (Figure 3B). We found an increased copy number of the ori2-minichromosome from $0.31 \pm 0.02$ in wt to $0.82 \pm 0.13$ in the strain with a chromosomal insertion of $c r t S$. Our data confirmed that $c r t S$ increases the ori2-minichromosome copy number and showed that a chromosomal crtS insertion is sufficient to this end.
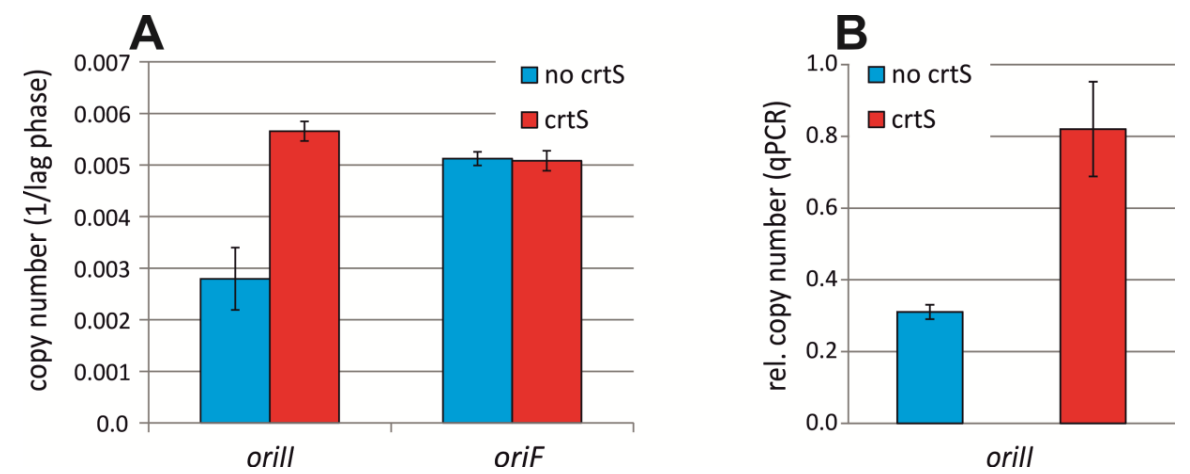

Figure 3. Copy numbers of secondary replicons in E. coli dependent on crtS. (A) Copy number of an ori2-based minichromosome in an E. coli strain without crtS (Strain NZ72) or with crtS-site insertion on the chromosome (Strain NZ140) was measured as inverse of the lag time for cells in medium with high concentrations of ampicillin $(500 \mu \mathrm{g} / \mathrm{mL})$. Strains carrying an oriF-based replicon and the crtS (Strain NZ141) or no crtS on the chromosome (Strain NZ119) were used as control. Data are the mean of three biological replicates with the indicated standard deviations. (B) Copy number of an ori2-minichromosome (pMA568) analyzed by qPCR-based marker frequency analysis relative to oriC. Mean values of three biological replicates are shown with the respective standard deviations.

We speculated that a crtS site could lead to more regular replication timing of the primary chromosome in the $E$. coli strain \#16 with ori2-driven chromosome replication. To make crtS replication dependent on the cell cycle, as is the case in V. cholerae, we constructed an oriC-minichromosome carrying a crtS site. However, transformation of strain \#16 failed by this replicon failed. To study this phenomenon in detail we quantified the number of colonies as a result of conjugating the replicon from a donor strain to either an E. coli wt, or strain \#16 with ori2-driven chromosomal replication. An oriC-minichromosome was efficiently transferred into a wt $E$. coli by conjugation, as was an oriC-minichromosome carrying a $c r t S$ site (Figure $4 \mathrm{~A}$ ). In contrast, neither of these two replicons could be transferred to strain \#16 via conjugation. These results indicated that it is the oriC on the extra replicon which causes some problem in the ori2 E. coli strain. As an alternative to test the effect of 
$c r t S$ on chromosomal ori2 replication, we constructed a replicon with the F-plasmid origin and a $c r t S$ site. Interestingly, this replicon could also not be transferred to strain \#16 (Figure 4B). One explanation for lacking transconjugants could be that the $\mathrm{crtS}$ site leads to repression of the extra replicon for example by strong binding of RctB. An alternative explanation would be that the crtS site effects ori2 replication on the primary chromosome in a way leading to cell death. To distinguish between these two possibilities we tested conjugation into a strain carrying oriC and ori2 on the primary E. coli chromosome (Figure 4B). If replication problems would be due to events on the extra replicon it should not be possible to conjugate into this strain. However, transconjugants were observed, indicating that some interference of the $c r t S$ site with ori2-based replication on the E. coli chromosome hinders extra replicons carrying a crtS site to be transferred to strain \#16.
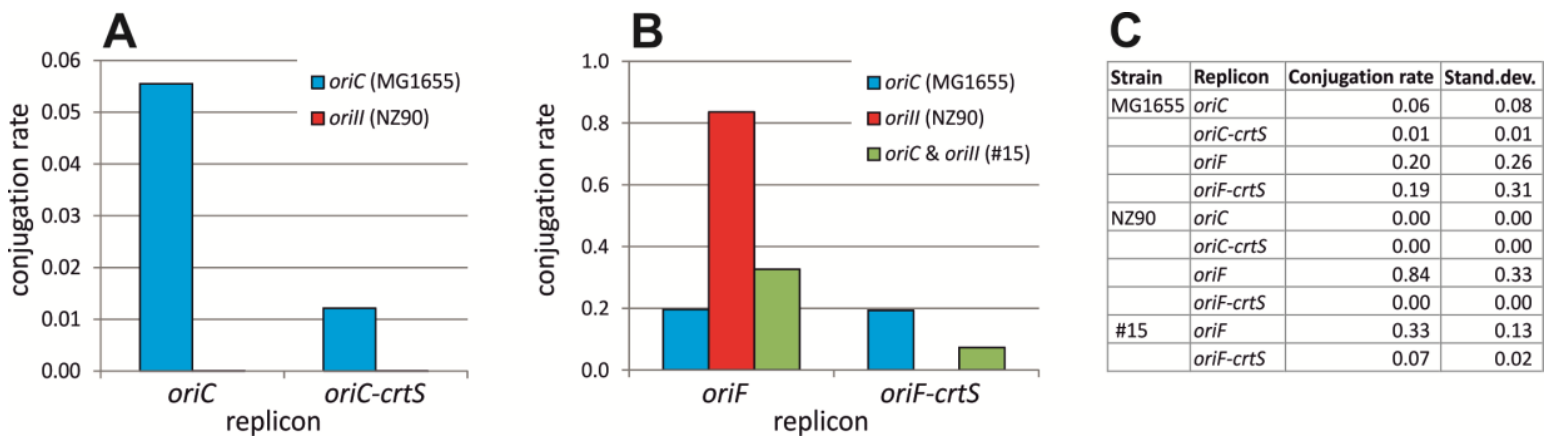

Figure 4. Conjugation rate of extra replicons to oriC and ori2 E. coli strains. (A) Transfer by conjugation was tested for oriC-minichromosomes carrying a crtS site (pMA200) or no crtS (pMA308) into E. coli with chromosome replication based on oriC (MG1655) or ori2 (NZ90). (B) Conjugation of oriF-based replicons with crtS (pMA206) or without (pMA899) into E. coli with oriC (MG1655), ori2 (NZ90) or oriC at the native site and ori2 at an ectopic site (\#15) [25,29]. Mean values of three biological replicates are shown in $(\mathbf{A}, \mathbf{B})$ with the actual numbers and standard deviations given in the table $(\mathbf{C})$.

\subsection{Assaying the DnaA-Box in ori2 for Its Role in Replication Initiation}

Our observation that an oriC-minichromosome could not be transferred to an E. coli strain with ori2-based chromosome replication suggested a mechanism of interference. Such an effect has been observed in cases where the two origins differ in their efficiency to initiate replication [13,34]. However, such interference is usually due to the competition or interference of factors used by both replication origins. One factor that both ori2 and oriC require for replication is DnaA. While the role of DnaA as initiator at oriC and ori1 is well studied, much less is known about DnaA activity at ori2. It has been established that ori2-dependent replication requires DnaA and that ori2 contains a DnaA box beside the RctB binding iterons, which appeared in a mutagenesis screen to be functionally important $[5,19]$. The role of the DnaA box was initially tested by the introduction of some mutations into a minichromosome carrying the minimal ori2 sequence [19]. Here, we constructed and tested some of these mutations as well as additional ones in a minichromosome system including both the entire ori2 and the flanking $r c t B$ and par $A B$ genes. Functionality of minichromosomes was tested by measuring their transformation efficiency of a wt $E$. coli. This efficiency was measured relative to transformation of the same replicon into a strain encoding the $\lambda$ pir gene, which allowed replication based on the oriR6K of the ori2-minichromosomes. Deletion, inversion or scrambling of the DnaA-box rendered ori2 nonfunctional, as seen by the inability of the respective replicons to transform a wt E. coli (Figure 5A). How well a DnaA box matches the consensus sequence determines the affinity of DnaA towards this site. Since the DnaA box within ori2 has the sequence of a high-affinity binding site, we tested the effect of changing this sequence to a weak or medium-strength DnaA box (Figure 5B). Both alternative DnaA boxes allowed ori2-minichromosome replication; however, the transformation efficiency was reduced, indicating that a high affinity DnaA box is needed to allow optimal functioning of ori2. The distance 
between the DnaA box and the first of six RctB binding iterons is 22 bps, placing the two proteins on the same face of the DNA helix. We tested the insertion or deletion of 5 bps between these sites which should shift the binding sites half of a DNA turn along (Figure 5C). Insertion and deletion to the right of the DnaA box (between DnaA box and iteron) greatly reduced the transformation efficiency in comparison to wt or to an insertion to the left. This finding indicated that the distance between the DnaA box and the iterons is critical for its functionality. Interestingly, a deletion to the left of the DnaA box also reduced the transformation efficiency.
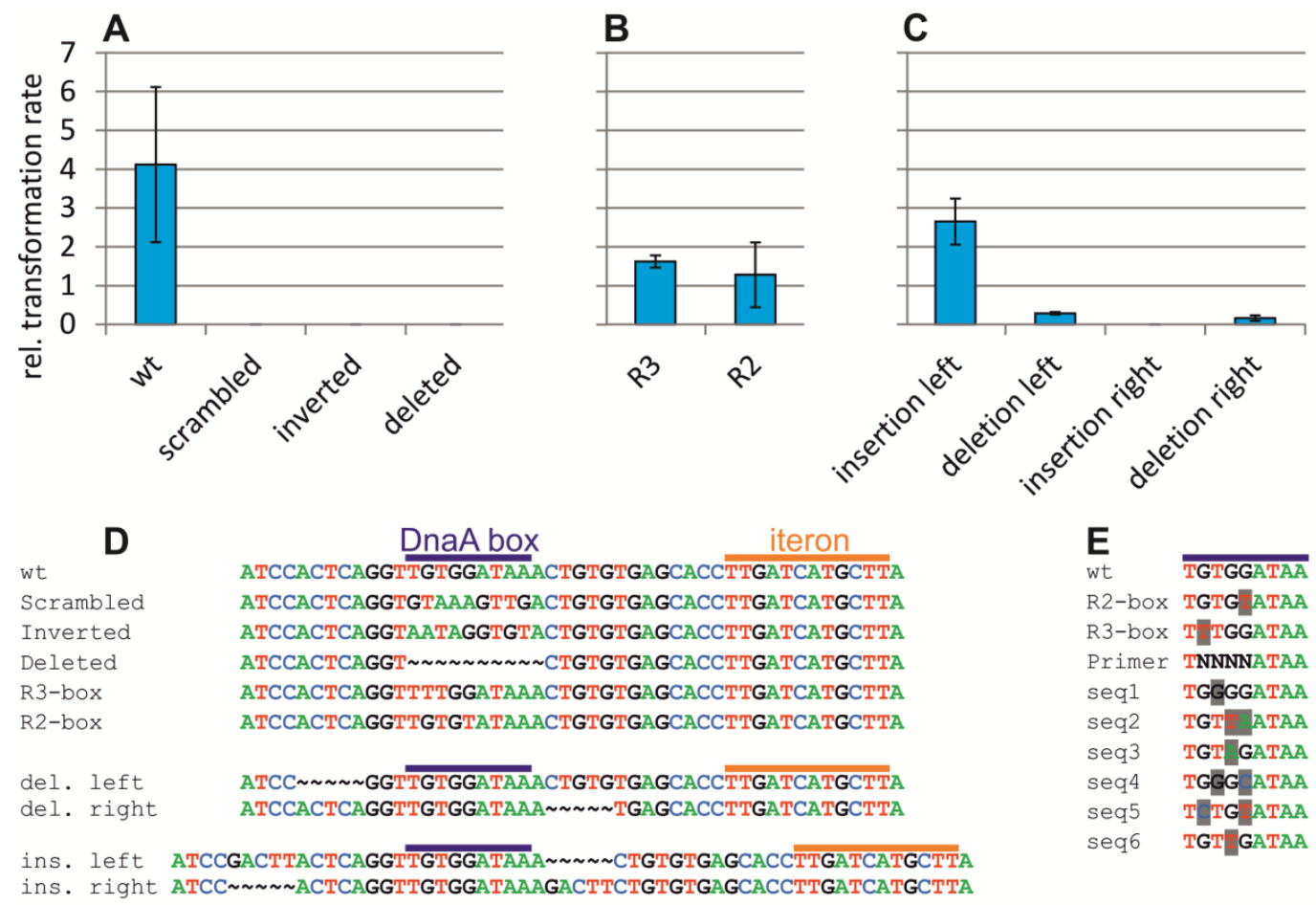

Figure 5. Mutation-based analysis of the DnaA box within ori2. (A-C) Ori2-based minichromosomes with different mutations at the DnaA box were tested for their ability to replicate by transformation into E. coli (XL1-Blue) or DH5 $\alpha \lambda$ pir. The latter was used as a control because all replicons carry an oriR6K which allows replication in strains encoding the initiator Pir. Values are ratios between respective colony numbers of three biological replicates with the indicated standard deviations. Relevant sequences are shown in (D) for DnaA boxes wt (pMA87), scrambled (pMA108), inverted (pMA109), deleted (pMA110), a weak DnaA box R3 (pMA111), a medium-strength DnaA box R2 (pMA112), a 5 bp insertion to the left of the DnaA box (pMA115) or the right (pMA114) or a 5 bp deletion to the left (pMA113) or right (pMA116) as indicated. (E) Sequences found by transformation of an assembled ori2-minichromosome with a mix of sequence combinations at positions 2-5 as indicated by " $\mathrm{N}$ " in the Primer sequence. DnaA-box sequences from oriC in E. coli are shown for comparison (wt, R2, R3). Six sequences found in the screen are shown with the nucleotides differing from the consensus DnaA box shaded in grey.

As an alternative approach to assess the importance of the DnaA box for ori2 functionality, we cloned the ori2 fragment into a plasmid based on a sequence library that substituted four nucleotides of the DnaA box with all possible 256 sequence combinations (Figure 5D). Transformation of the respective minichromosome mix into E. coli wt should then allow selection of functional replication origins. Sequencing of ori2 sequences derived from such experiments revealed six different sequences that could function in place of the original DnaA box (Figure 5D). In all sequences found, two or three out of four nucleotides matched the DnaA box consensus, confirming the importance of the DnaA box on one hand and some potential for variation on the other, supporting the above results on introduction of weaker DnaA boxes. 


\subsection{Vibrepin Does Not Inhibit ori2-Dependent Replication}

A screen for substances that lead to growth inhibition of an E. coli strain carrying an ori2 minichromosome uncovered such activity of 3-(3,4-dichlorophenyl)cyclopropane-1,1,2,2tetracarbonitrile, designated as "vibrepin" (for Vibrio replication inhibitor) [35]. It was found that vibrepin interferes with ori2-opening activity of RctB [35]. We reasoned that vibrepin should inhibit growth of E. coli strain \#16 with chromosomal replication solely based on ori2, and as such the strain might be useful to identify additional ori2-specific inhibitors in the future in order to derive $V$. cholerae-selective antibiotics. Comparing the lag-phase duration of an E. coli wt with and without vibrepin revealed a slightly longer lag phase $(13.5 \%)$ in medium supplemented with $16 \mu \mathrm{g} / \mathrm{mL}$ vibrepin (Figure 6A). Surprisingly, this difference was similar in the ori2 strain (Figure 6A) indicating that vibrepin does not significantly inhibit ori2 initiation in this context. As a second line of evidence, we compared the effect of vibrepin on E. coli cells carrying extra replicons based on either ori2, oriC or the F-plasmid origin (Figure 6B). The elongation of lag phases caused by vibrepin was similar for all three replicons, confirming the above results that vibrepin was not acting on ori2 specifically (Figure 6B). To test vibrepin activity on ori2 in V. cholerae directly, we compared its effect on growth of (i) strain N16961 carrying a secondary ori2-based chromosome [6], (ii) strain MCH1 with a fused chromosome driven by ori1 and lacking ori2 [36], and (iii) the recently characterized V. cholerae strain NSCVI with fused chromosomes and intact copies of ori1 and ori2 [37]. If vibrepin acts against ori2 specifically, one would expect strain N16961 to be inhibited but not the two other strains. However, we found vibrepin to have an effect on the lag phase duration for all three strains, indicating that vibrepin inhibits $V$. cholerae growth, but not based on interference at ori2 (Figure 6C).
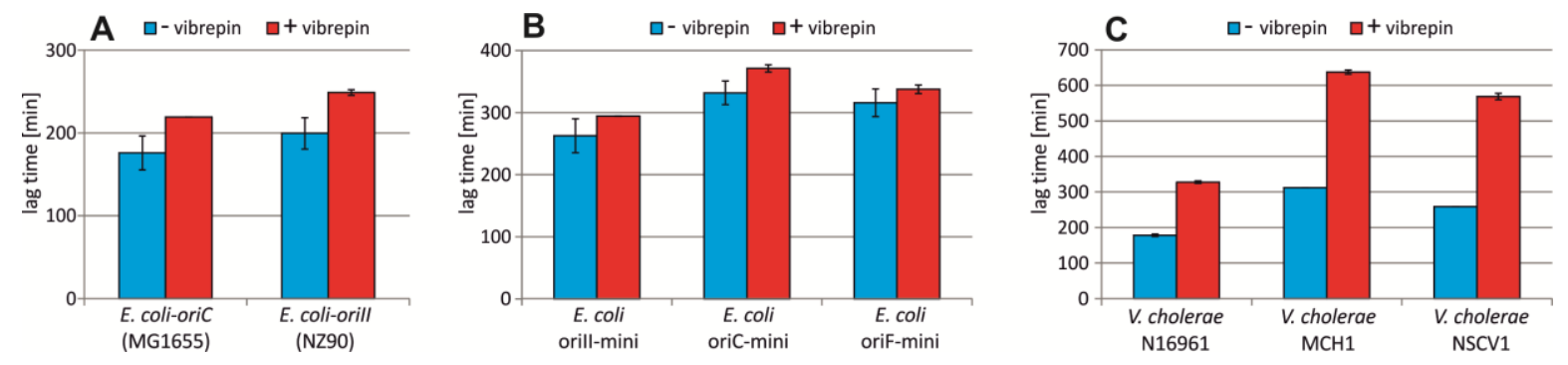

Figure 6. Effect of vibrepin on ori2-dependent replication. Lag time (time until OD $=0.1$ was reached) is shown as the mean value of three replicates, with the respective standard deviations, in medium without vibrepin (blue) or with vibrepin (red). Vibrepin concentrations were $16 \mu \mathrm{g} / \mathrm{mL}$ for $E$. coli strains (A-B) and $1.6 \mu \mathrm{g} / \mathrm{mL}$ for $V$. cholerae strains (C). Analyzed E. coli strains replicated their chromosome based on oriC (MG1655) or ori1 (NZ90) (A) or carried an extra minireplicon with ori2 (pMA100), oriC (pMA106) or oriF (pMA129) [38] (B) as indicated. V. cholerae strains are the standard two-chromosome strain N16961 [6], an engineered derivative of N16961 with fused chromosomes (MCH1) [36] or a natural isolate with fused chromosomes (NSCV1) [37].

\section{6. ori2 Can Replace oriC in E. coli}

We have characterized here an E. coli strain with an ectopic ori2 insertion about 500 kbps away from oriC combined with a deletion of oriC and used it to study biological features related to ori2-based replication. The value of such a system was appreciated before but attempts to replace oriC by ori2 were unsuccessful [13]. We reasoned that such an exchange of oriC to ori2 should be possible in general based on the findings outlined above. Indeed, we were able to replace the oriC sequence in $E$. coli strain MG1655 with the full $V$. cholerae ori2 sequence, including the flanking genes $r c t B$ and parAB (Strain NZ138, see Figure 7A and Methods section for details). Successful oriC replacement was confirmed by the inability of a $\Delta$ dam allele to be transferred by $\mathrm{P} 1$ transduction to the constructed strain, similar to what was found for strain \#16 above. A comparison of a wt oriC-strain, to this new oriC to ori2 exchange strain (NZ138) revealed a slight increase of doubling time (21.6 vs. 22.6 respectively; 
Figure 7B). The strain with the ectopic ori2 insertion (NZ90) grew slower (27 min doubling time). DNA contents, as measured by flow cytometry were lower for both ori2 strains compared to the oriC wt strain (Figure 7B, middle panel). The protein content as measure of the cell size varied slightly with cells of strain NZ90 being smallest on average and NZ138 being the largest cells (Figure 7B, right panel). In summary, characteristics of the newly constructed stain NZ138 differ from those of strain $\mathrm{NZ90}$ and are more similar to a wt $E$. coli with oriC-driven replication. We believe that this E. coli ori2 strain NZ138 will be of great help to derive new insights into ori2-dependent replication and screen for new $V$. cholerae specific replication inhibitors in the future.
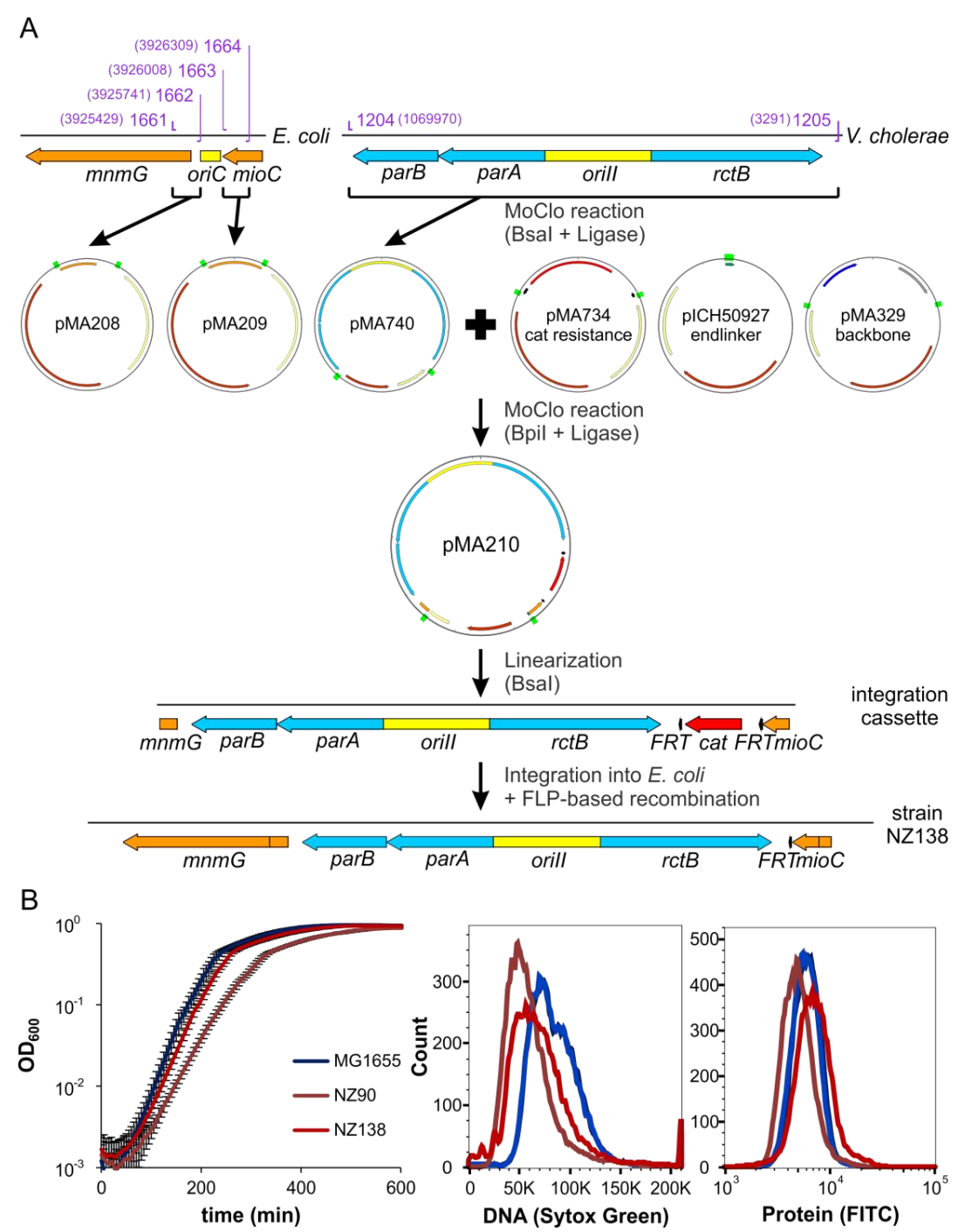

Figure 7. Construction and characterization of strain NZ138. (A) Scheme of NZ138 construction. Genes are indicated by arrows, origins of replication and the truncated end of $m n m G$ by blocks. Genes of $V$. cholerae are colored blue, genes of $E$. coli orange, resistance genes red, FRT-sites black and origins of replication yellow. Green rectangles indicate BsaI and BpiI restriction sites. Binding sites of oligonucleotides are indicated in purple, numbers in brackets are genome positions of 5 '-ends of the binding sites. Genomic and linearized DNA is indicated by grey lines, plasmids by circles. (B) Growth, DNA content and protein content of NZ138 compared to MG1655 and NZ90. All strains were grown in LB medium. For growth curves, five replicates for each strain were grown in a 96-well plate at $37^{\circ} \mathrm{C}$. For determination of DNA and protein content, samples were taken in exponential phase and fixed with ethanol. The samples were split, stained with SYTOX Green (DNA) or FITC (protein) and analyzed by flow cytometry. 


\section{Discussion}

DNA replication is an attractive target for the development of antimicrobials. However, engineered systems are needed to be able to search specifically for chemicals targeted against the replication mechanism of interest. Such engineering approaches have for example used expression of hyperactive mutant proteins that kill the cells unless a chemical component suppresses their action [39]. The replication system of the secondary $V$. cholerae chromosome is especially interesting in respect to the development of antimicrobials because it is unique in the Vibrionaceae. The replication origin ori 2 can be studied in E. coli regarding general functionality and drug development using so-called minichromosomes $[5,35]$. These are plasmid-like replicons carrying a chromosomal replication origin and usually a conditional plasmid origin to be able to construct the replicons in the first place [40]. Minichromosomes are an important tool to, for example, identify the minimal region of a chromosome that functions as its origin of replication. Due to their easier genetic manipulation, they are also used frequently to characterize replication origins further-for example, in identification of the role of individual DNA motifs, as demonstrated with the DnaA box in ori2 above (Figure 5). However, minichromosome-based studies also have drawbacks in both their small size and their competition with the chromosomal replication origin. OriC-minichromosomes have high copy numbers due to a lack of an equipartition mechanism [41]. The competition can lead to integration of minichromosomes into the primary chromosome [42]. An alternative to minichromosomes is the substitution of native chromosomal replication origins with the ori of interest. For instance, such an approach was instrumental in order to study the role of Dam methyltransferase and SeqA for V. cholerae ori1 based replication $[13,14]$. However, while it is easy to see if a certain mutation is rendering a replication origin non-functional when using minichromosomes, investigating replication origins driving replication of the primary chromosome is not straightforward, as replication here is an essential process. One solution to this problem is the insertion of an additional plasmid origin which can be switched off, by, for example, repression of its initiator protein [43]. If depletion of an inducer leads to cell death, the origin of interest must be non-functional [43]. An alternative to this approach is the analysis of chromosomes carrying two functional replication origins which, for example, allow conclusions on their replication timing to be drawn by comparison with their MFA profiles [29]. The study showed that E. coli oriC and $V$. cholerae ori2 can coexist on the chromosome and both be active [29]. This is consistent with many studies using ori2-based minichromosomes to study $V$. cholerae replication in E. coli. It was thus surprising that an oriC-minichromosome could not be transferred to an E. coli strain with chromosomal replication based on $V$. cholerae ori2 (Figure $4 \mathrm{~A}$ ). We propose three possible reasons to explain this phenomenon; (i) the oriC-minichromosome leads to ori2-based over-replication of the chromosome, (ii) the oriC-minichromosome leads to ori2-based under-replication of the chromosome, and (iii) the interference of oriC and ori2 hinders oriC-dependent minichromosome replication. Regarding the first possibility, over-replication is a commonly observed phenomenon caused by different mutations that might be tolerated in some cases and leading to cell death in others [44-47]. The differentiation between the other two hypotheses is related to the question of which origin can compete better for factors needed for replication initiation at both oriC and ori2. Three known protein factors are relevant in this context; SeqA, Dam and DnaA. SeqA is a negative regulator of initiation at both replication origins and competition should therefore lead to more initiations but never to a blocking of replication [13,48,49]. The role of Dam is to methylate the GATCs which occur at both replication origins, but the speed of the methylation process is so fast that a changed ori2 methylation due to an increased number of GATCs on the oriC minichromosome is unlikely. These considerations leave DnaA remaining as the factor required by both ori 2 and oriC. It is well conceivable that oriC would win a competition for DnaA against ori2 since it comprises multiple DnaA binding sites, while ori2 has only a single one. Even more DnaA is directed away from ori2 when the oriC on the minichromosome occurs in multiple copies $[38,41]$. A single oriC copy on the chromosome could also inhibit ori2-driven replication initiation, but perhaps only to a minor extent. Interestingly, this seems to be the case in practice, as copy numbers of ori 2 in $E$. coli strains that carry the native oriC are lower than oriC or similar. This 
is the case for ori 2 minichromosomes as well as ectopic ori2 insertions $[29,33,38]$. This is remarkable, since ori2 itself was shown to lead to over-initiation and higher chromosomal copy numbers without a competing oriC in the cell (Figure 1). These findings suggested that the availability of DnaA limits initiation at ori2. However, replication of $\mathrm{Chr} 2$ in $V$. cholerae did not increase with over-expression of DnaA while Chr1 copies were amplified [7]. One possible explanation for this discrepancy is that it is not the amount of DnaA per se that is important, but the availability of ATP vs. ADP-bound versions of this protein. Our data seem to suggest that DnaA-ATP is actually functional at ori2, based on our finding that lower affinity DnaA boxes can replace the native DnaA box (Figure 5B,E). These sites are able to bind ATP-DnaA but not ADP-DnaA [50]. The exact role of DnaA in replication initiation at ori2 remains to be uncovered but mutational analyses of ori2-based minichromosomes presented here and in a previous study provide first insights (Figure 5) [19].

It appears that DnaA may add just another layer of regulation to the regulation of $\mathrm{Chr} 2$ replication in $V$. cholerae alongside SeqA, Dam methylation, and the recently found $c r t S$ site. The latter was found here to increase the copy number of an ori2-minichromosome when it was itself located on the E. coli chromosome (Figure 3). If a slight increase in the number of initiation events at ori2 is the general effect of $c r t S$, it is hard to find an explanation for the result where an F-plasmid-origin-based replicon carrying a crtS site could not be transformed into the ori 2 E. coli strain (Figure 4). Notably, we were also not able to transfer the chromosomal crtS insertion into the ori2-strain. We suggest that $c r t S$ and ori 2 are actually regulated in a way that adjusts their copy numbers to be similar. This is what was found in $V$. cholerae, where copy numbers of Chr2 increased when the crtS was moved closer to ori1, coinciding with an increased copy number of $c r t S$. Comparison to previous studies on $c r t S$ in $E$. coli are difficult because they used a three plasmid system with ori2, $r c t B$ and $c r t S$ each on an extra replicon [20]. Certainly, further research is needed to fully understand the mechanistic crtS-to-ori2 interrelation. Nevertheless, we consider the heterologous E. coli system with chromosomal insertions of ori2 and crtS presented here to be highly valuable in the study of the complex replication regulation system of $V$. cholerae in a simplified synthetic system. Ori2 was used previously to search for replication inhibitors specific for $V$. cholerae and we anticipate that corresponding studies might be extended to the $\mathrm{crtS}$ site mechanism potentially with the experimental system presented here and its further development [35].

We have used the ori2-test system established here to investigate the activity of the chemical compound 3-(3,4-dichlorophenyl)cyclopropane-1,1,2,2-tetracarbonitrile, designated as "vibrepin" (for Vibrio replication inhibitor). Our results confirm the inhibition of $V$. cholerae growth that was found previously (Figure 6C) [35]. Surprisingly, vibrepin did not inhibit growth of E. coli strain NZ90 with ori2-driven chromosome replication more than that of a wt $E$. coli strain with oriC-based replication. This finding contradicts previous results showing that RctB is specifically inhibited by vibrepin both in vivo and in vitro [35]. This conclusion was also based on a plasmid-based ori2-system in E. coli similar to our minichromosome approach (Figure 6B) [35]. However, one difference of our replicon to the previously used one is the inclusion of the parAB2 operon, encoding the partitioning proteins. Also, the E. coli strains with ori2-driven replication of the primary chromosome studied here, encode the parAB2 operon. Notably, ParB2 was shown to participate in regulation of initiation at ori2 [51]. One possibility to explain the contradicting results might thus be linked to the role of ParB2 in DNA replication initiation. It could, for example, be that ParB2 counteracts the activity of vibrepin against RctB in a yet unknown fashion yet to be discovered. Interestingly, the previous study suggested that vibrepin might have other targets in addition to RctB within $V$. cholerae. This note supports the need for heterologous systems as established in the project presented here to be able to determine specificities of inhibitors. 


\section{Materials and Methods}

\subsection{Bacterial Strains, Plasmids, Oligonucleotides, and Culture Conditions}

Strains, plasmids and oligonucleotides are listed in Table S1-S3. Pre-cultures of E. coli were grown in $3 \mathrm{~mL}$ LB medium. Antibiotics and inducer were used with the following concentrations if not indicated otherwise: ampicillin $(100 \mu \mathrm{g} / \mathrm{mL})$, kanamycin $(35 \mu \mathrm{g} / \mathrm{mL})$, chloramphenicol $(35 \mu \mathrm{g} / \mathrm{mL})$. Growth curves were measured in 96-well plates in a microplate reader (Victor X3 Multilabel plate reader, PerkinElmer or Infinite M200pro multimode microplate reader, Tecan, Männedorf, Switzerland) at $37^{\circ} \mathrm{C}$. The $150 \mu \mathrm{L}$ of main culture was inoculated 1:1000 and covered with $70 \mu \mathrm{L}$ of mineral oil. Optical density was measured in 5 or 6-minute intervals.

\subsection{P1 Transduction}

P1vir transduction was carried out as described [52]. Equal cell numbers of strains \#1 and NZ90 were incubated with the same P1vir lysate diluted 1:10 in steps to $10^{-3}$. Cells were plated after a $1 \mathrm{~h}$ recovery, plated on selective medium and incubated overnight. Colonies resulting from transduction with P1vir lysate dilution of $10^{-2}$ were considered for all experiments with colony numbers ranging from 0 to 300 .

\subsection{Conjugation}

The donor and acceptor strains were grown overnight and cell numbers adjusted to $\mathrm{OD}_{600} 3.0$. $100 \mu \mathrm{L}$ of cells were washed three times in LB medium supplemented with $300 \mu \mathrm{M}$ DAP to remove antibiotics. $50 \mu \mathrm{L}$ of both cell suspensions were mixed and $50 \mu \mathrm{L}$ of the mix spotted on an LB-agar plate containing DAP. Conjugations were incubated for $5 \mathrm{~h}$ at $37^{\circ} \mathrm{C}$ and about $1 / 3$ of the drop scratched off the plate and re-suspended in $1 \mathrm{~mL}$ LB medium. Cells were washed three times in $1 \mathrm{~mL}$ LB and finally re-suspended in $100 \mu \mathrm{L}$ of dilution buffer. Suspensions were diluted stepwise 1:10 until $10^{-9}$ and $20 \mu \mathrm{L}$ of each dilution plated on LB with selection for the transconjugants (LB-amp without DAP) and the acceptor cells (LB without DAP), respectively. Plates with colony numbers suitable for counting were selected after overnight incubation and the ratio between transconjugants and acceptor calculated as measure of conjugation rate.

\subsection{Quantification of Replicon Copy Numbers by $q P C R$}

In exponential growth phase, $1 \mathrm{~mL}$ culture of the E. coli strains NZ72 and NZ140 grown in LB-amp was harvested by centrifugation at $15,000 \times g$ for $4 \mathrm{~min}$. The cells were stored at $-20^{\circ} \mathrm{C}$. After thawing on ice, the sample were re-suspended in $1 \mathrm{~mL}$ water and incubated at $95^{\circ} \mathrm{C}$ for $10 \mathrm{~min}$. According to the formula $\mathrm{OD}_{600} 1=8 \times 10^{5}$ cells $/ \mu \mathrm{L}$, the samples were diluted to $1.25 \times 10^{4}$ cells $/ \mu \mathrm{L}$. The $E$. coli strain FSK18 was used as reference. It was grown in LB to early exponential growth phase and incubated with $150 \mu \mathrm{g} / \mathrm{mL}$ rifampicin and $10 \mu \mathrm{g} / \mathrm{mL}$ cephalexin at $37^{\circ} \mathrm{C}$ for $3.5 \mathrm{~h}$. Each reaction was carried out in triplicates of $10 \mu \mathrm{L}$. Primer sets for oriC (3921366fw, 3921366rv, 3921366pr) and synVicII (ori2fw, ori2rv, ori2probe) were used in separate reactions. Three biological replicates were analyzed three times each. Ratios of synVicII to oriC were calculated relative to strain FSK18 containing the genomic regions that are template for the oriC and synVicII primer sets (see above). qPCR reactions were composed of $5 \mu \mathrm{L}$ KAPA Probe Fast qPCR mastermix Universal 2× (peqlab, Erlangen, Germany), $1 \mu \mathrm{L}$ primer mix and $4 \mu \mathrm{L}$ cell suspension. The $250 \mu \mathrm{L}$ primer mix was prepared for each set of primer and contains $22.5 \mu \mathrm{L}$ primer fw $(100 \mathrm{pmol} / \mu \mathrm{L}), 22.5 \mu \mathrm{L}$ primer rv $(100 \mathrm{pmol} / \mu \mathrm{L}), 6.25 \mu \mathrm{L}$ probe (5'-Fam/3'-Tamra, $100 \mathrm{pmol} / \mu \mathrm{L}$ ), $50 \mu \mathrm{L}$ Rox Reference Dye Low $50 \times$ (peqlab) and $148.75 \mu \mathrm{L}$ water. qPCR reactions were performed in the real-time cycler qTower (Analytik Jena AG, Jena, Germany) with the following program: $1,95^{\circ} \mathrm{C}$ for $3 \mathrm{~min} ; 2,95^{\circ} \mathrm{C}$ for $3 \mathrm{~s} ; 3,55^{\circ} \mathrm{C}$ for $20 \mathrm{~s}$; and 4 , fluorescence read. Steps 2-4 were repeated 45 times. The determination of the CT-values was carried out with the software qPCRsoft (Analytik Jena AG, Jena, Germany) without using the rox reference. 


\subsection{Quantification of Replicon Copy Number via Antibiotic Sensitivity}

Analysis of the copy-up effect of $c r t S$ was done as described in [33]. Cells were grown in LB medium with either 100 or $500 \mu \mathrm{g} / \mathrm{mL}$ ampicillin at $37^{\circ} \mathrm{C}$ in 96 -well plates in a microplate reader (Infinite M200pro multimode microplate reader, Tecan). The main culture (150 $\mu \mathrm{L})$ was inoculated 1:1000 and growth curves recorded for $15 \mathrm{~h}$. For better visualization, 1 divided by the time needed to reach an $\mathrm{OD}_{600}$ of 0.1 was defined as measure of the copy number.

\subsection{Comparative Genomic Hybridization}

Exponentially growing cells in $\mathrm{LB}\left(\mathrm{OD}_{600}=0.15\right)$ were mixed in a 1:1 ratio with cold killing buffer. Strain \#1 (wt MG1655 with an inserted to site) grown in AB Glu-CAA until stationary phase was used as a reference. All samples were centrifuged at $4{ }^{\circ} \mathrm{C}$ and cells were resuspended in $300 \mu \mathrm{L}$ immunoprecipitation buffer. Cells were sonicated via Bioruptor ${ }^{\circledR}$ Plus (Diagenode Diagnosics) (48 cycles of $30 \mathrm{~s}$ with $30 \mathrm{~s}$ cooling) to receive DNA fragments of around $500 \mathrm{bp}$. The cell extract was centrifuged and the supernatant was transferred to a new reaction tube. TE buffer $(300 \mu \mathrm{L})$ and $2 \mu \mathrm{L}$ RNase A ( $10 \mathrm{mg} / \mathrm{mL}$ ) were added, and samples were incubated at $65^{\circ} \mathrm{C}$ for $90 \mathrm{~min}$. DNA was extracted with phenol/chloroform. DNA ( $400 \mathrm{ng} ; 20 \mathrm{ng} / \mathrm{mL}$ in $20 \mu \mathrm{L}$ ) was labeled with Cy3-dCTP (sample) or Cy5-dCTP (reference), mixed and hybridized to whole genome microarrays from Agilent $(8 \times 15 \mathrm{k})$ as described [53]. Arrays were scanned on an Agilent SureScan High Resolution Scanner. Spot intensities were extracted via AgilentScan Control software. Ratios of dye intensities were calculated and normalized to the array-wide average using R. A Loess fitting was applied to the microarray data to obtain a locally weighted average (shown as the colored line in CGH plot). For this average line, we detected maxima and minima. The maximal and minimal positions were used to dissect the data set in subsets delimited by the extrema. For these subsets, a linear regression line was determined, and the coordinates of the intersection points were taken as final maxima and minima.

\subsection{Flow Cytometry}

To generate Rif/Ceph run out samples, cells were grown in LB-medium [with Ohly ${ }^{\circledR}$ yeast extract] and treated with $150 \mu \mathrm{g} / \mathrm{mL}$ rifampicin and $10 \mu \mathrm{g} / \mathrm{mL}$ cephalexin in the early exponential phase for more than three generations $(2-3 \mathrm{~h})$, allowing them to finish ongoing rounds of replication [54]. For exponential phase samples, cells were grown in LB until the early exponential phase. The cells were harvested and washed twice in TBS $(0.1 \mathrm{M}$ Tris- $\mathrm{HCl} \mathrm{pH} \mathrm{7.5,} 0.75 \mathrm{M} \mathrm{NaCl})$. They were fixed in $100 \mu \mathrm{L} \mathrm{TBS}$ and $1 \mathrm{~mL} \mathrm{77 \%}$ ethanol and stored at least overnight at $4{ }^{\circ} \mathrm{C}$. For run-out experiments, cell samples were washed and diluted in $0.1 \mathrm{M}$ phosphate buffer, $\mathrm{pH} 9.0$ (PB buffer). Proteins were stained overnight with $3 \mu \mathrm{g} / \mathrm{mL}$ FITC solution (PB buffer) at $4{ }^{\circ} \mathrm{C}$. Afterwards, cells were stained with Hoechst 33,258 as has been outlined before [38]. They were analyzed on LSR II flow cytometer (BD Biosciences) and flow cytometry measurements were carried out as described [55]. E. coli MG1655 cells grown exponentially in $\mathrm{AB}$-acetate and stained with Hoechst only served as an internal standard and were added to every sample. For DNA-stained exponential grown cells, the samples were washed in $0.5 \mathrm{M}$ sodium-citrate and treated with $5 \mathrm{ng} / \mathrm{mL}$ RNase A in $0.5 \mathrm{M}$ sodium-citrate for $4 \mathrm{~h}$ at $50{ }^{\circ} \mathrm{C}$. They were stained with $250 \mathrm{nM}$ SYTOX ${ }^{\circledR}$ Green Nucleic Acid Stain (Thermo Fisher Scientific, Waltham, MA, USA ) and analyzed on Fortessa Flow Cytometer (BD Biosciences, San Jose, CA, USA). The SYTOX ${ }^{\circledR}$ Green fluorescence was measured through a $530 / 30 \mathrm{~nm}$ bandpass filter. E. coli MG1655 cells grown exponentially in AB-acetate and stained with SYTOX ${ }^{\circledR}$ Green served as standard. For protein-stained exponential grown cells, samples were treated with FITC as described above. The cells were washed with TBS and analyzed on Fortessa Flow Cytometer (BD Biosciences). The FITC fluorescence was measured through a 530/30 nm bandpass filter. Data was processed with the software FlowJo (Treestar, Ashland, OR, USA). 


\subsection{Fluorescence Microscopy and Data Evaluation}

Cells were grown in $\mathrm{AB}$ glucose $\mathrm{CAA}$ to $\mathrm{OD}_{450} \sim 0.15$. $1 \mathrm{~mL}$ of the culture was harvested by centrifugation and cells re-suspended in $25 \mu \mathrm{L}$ fresh AB glucose CAA. Cells $(2 \mu \mathrm{L})$ were transferred to $1 \%$ agarose pads containing $1 \%$ TAE. Fluorescence microscopy was performed with a Nikon Eclipse Ti-E microscope with a phase-contrast Plan Apo 1 oil objective (100; numerical aperture, 1.45) with the AHF HC filter set F36-528 YFP (excitation band pass [ex bp] 500/24-nm, beam splitter [bs] 515-nm, and emission [em] bp 535/30-nm filters) and an Argon Ion Laser (Melles Griot, Rochester, NY, USA). Images were acquired with an Andor iXon3 885 electron-multiplying charge-coupled device (EMCCD) camera. For quantification of fluorescence foci, 20 images were taken for every strain and the first 700 cells were used for further analyses. Images were analyzed by Fiji using the MircobeJ plugin [56].

\subsection{Plasmid Construction}

Plasmid pMA200 was constructed by the cutting of pMA308 with I-SceI and insertion of the crtS site amplified with primers 1593 and 1613 with $V$. cholerae chromosomal DNA as the template, by Gibson assembly [57]. Plasmid pMA308 was constructed by cutting pMA135 with AscI and inserting oriC amplified with primers 1349 and 1350 with E. coli MG1655 DNA as the template. Plasmid pMA899 was constructed by cutting of pMA135 with AscI and insertion of oriF, amplified with primers 1487 and 1488 with pMA129 as the template. Plasmid pMA206 was constructed by cutting of pMA899 with I-SceI and insertion of the $c r t S$ site, amplified with primers 1593 and 1613 with $V$. cholerae chromosomal DNA as the template, by Gibson assembly. Plasmid pMA568 was constructed by cutting pMA132 with I-SceI and insertion of a NotI restriction site flanked lac $Z$ cassette amplified using primers 1002 and 1004. Plasmid pMA208 was constructed by a MoClo-reaction (with BsaI) with plasmid pMA350 and a PCR fragment amplified with primers 1661 and 1662 with E. coli DNA as the template. MoClo was carried out as described $[27,58]$. Plasmid pMA209 was constructed by a MoClo-reaction with plasmid pMA353 and a PCR fragment amplified with primers 1663 and 1664 with E. coli DNA as template. Plasmid pMA740 was constructed by a MoClo reaction with plasmid pMA351 and a PCR fragment amplified with primers 1204 and 1205 and plasmid pMA650 as the template to amplify an ori2 without bpiI or BsaI restriction sites. Plasmid pMA734 was constructed by a MoClo reaction with plasmid pMA352 and a chloramphenicol resistance cassette flanked by FRT sites generated by PCR with primers 703 and 704. Plasmid pMA210 was constructed in a MoClo reaction (with bpiI) including plasmids pMA208, pMA209, pMA329, pMA734, pMA740 and pICH50927. Plasmid pMA157 was constructed by a MoClo reaction with plasmid pMA349 (with BsaI) and a PCR fragment amplified with primers 1439 and 1440 and V. cholerae chromosomal DNA as template. Plasmid pMA431 was constructed by a MoClo reaction (BsaI) with plasmid pMA350 and a kanamycin resistance cassette flanked by FRT sites generated by PCR with primers 1455 and 1456. Plasmid pMA710 was constructed as described for pMA711 before with pMA351 as MoClo vector instead pMA352 [27]. Plasmid pMA207 was constructed in a MoClo reaction (with bpiI) including plasmids pMA709, pMA710, pMA327, pMA431, pMA157 and pICH50900. Minichromosomes pMA108-116 were constructed by Gibson Assembly [57]. Inserts were amplified from pMA87 by PCR with primers that contain homologous sequences to sequences on pMA90, which contains only half of the ori2 sequences, with the part missing starting close to the DnaA box. Primers used are given in supplementary Table S4. The vector pMA90 was linearized with NotI before assembly with the PCR products. Chemically competent E. coli DH5 $\alpha \lambda$ pir cells, which can replicate these minichromosomes using their R2K origin [59], were transformed with the Gibson Assembly products. Colonies were screened by colony PCR with primers 14 and 16. Primer 16 is located in a sequence missing in pMA90 but present in minichromosomes with a full ori2. All constructs were verified by sequencing. 


\subsection{Strain Construction}

Strain SM113 was constructed by introduction of the FROS array by P1 transduction and subsequent FRT recombination as described previously for strain SM112 [27]. To integrate ori2 into oriC in E. coli we used a DNA fragment consisting of ori2 and a chloramphenicol resistance cassette flanked by regions beside oriC (parts of mioC and $m n m G$ ) for homologous recombination (Figure 7). The subsequent DNA fragment was generated by releasing the insert of plasmid pMA210 by cutting with BsaI and transformed into strain AB330 for recombineering. Exchange of oriC for ori2 was confirmed by PCR and flow cytometry and the respective strain designated NZ135. The ori2 insertion was transferred to E. coli MG1655 wt by P1 transduction to give strain NZ134. Subsequently the CAT cassette was removed via pCP20-based recombination resulting in strain NZ138 [60]. Introduction of the $c r t S$ site into the chromosome was similar to ori2 into oriC but using pMA207 instead of pMA210.

Supplementary Materials: The following are available online at www.mdpi.com/2079-6382/7/1/3/s1, Table S1: Strains used in this study, Table S2: Plasmids used in this study, Table S3: Oligonucleotides used in this study, Table S4: Oligonucleotides used for construction of mutated ori2-minichromosomes.

Acknowledgments: We are grateful to Sonja Messerschmidt, Neda Farmani and Joel Eichmann for contributions to the experiments described here and to Celine Zumkeller for help with preparation of the manuscript. Beatrice Schofield is acknowledged for careful reading and editing of the manuscript. We thank Shanmuga Sozhamanan for providing strain NSCV1 as well as Xiquan Liang and Federico Katzen for sending strains \#1, \#15 and \#16. We acknowledge the Flow Cytometry Core Facility (ZTI, Marburg, Germany) for providing devices and help. This work was supported within the LOEWE program of the State of Hesse and a grant of the Deutsche Forschungsgemeinschaft (Grant No. WA 2713/4-1).

Author Contributions: N.S., S.M., D.S. and T.W. conceived and designed the experiments; N.S., S.M., T.S., M.B. and F.S.K. performed the experiments; N.S., S.M., T.S., M.B., F.S.K., D.S. and T.W. analyzed the data; T.W. wrote the paper.

Conflicts of Interest: The authors declare no conflict of interest.

\section{References}

1. Kuzminov, A. The precarious prokaryotic chromosome. J. Bacteriol. 2014, 196, 1793-1806. [CrossRef] [PubMed]

2. Jha, J.K.; Baek, J.H.; Venkova-Canova, T.; Chattoraj, D.K. Chromosome dynamics in multichromosome bacteria. Biochim. Biophys. Acta 2012, 1819, 826-829. [CrossRef] [PubMed]

3. Chen, C.W.; Huang, C.H.; Lee, H.H.; Tsai, H.H.; Kirby, R. Once the circle has been broken: Dynamics and evolution of Streptomyces chromosomes. Trends Genet. 2002, 18, 522-529. [CrossRef]

4. Val, M.E.; Soler-Bistue, A.; Bland, M.J.; Mazel, D. Management of multipartite genomes: The Vibrio cholerae model. Curr. Opin. Microbiol. 2014, 22, 120-126. [CrossRef] [PubMed]

5. Egan, E.S.; Waldor, M.K. Distinct replication requirements for the two Vibrio cholerae chromosomes. Cell 2003, 114, 521-530. [CrossRef]

6. Heidelberg, J.F.; Eisen, J.A.; Nelson, W.C.; Clayton, R.A.; Gwinn, M.L.; Dodson, R.J.; Haft, D.H.; Hickey, E.K.; Peterson, J.D.; Umayam, L.; et al. DNA sequence of both chromosomes of the cholera pathogen Vibrio cholerae. Nature 2000, 406, 477-483. [PubMed]

7. Duigou, S.; Knudsen, K.G.; Skovgaard, O.; Egan, E.S.; Lobner-Olesen, A.; Waldor, M.K. Independent control of replication initiation of the two Vibrio cholerae chromosomes by DnaA and RctB. J. Bacteriol. 2006, 188, 6419-6424. [CrossRef] [PubMed]

8. Duigou, S.; Yamaichi, Y.; Waldor, M.K. ATP negatively regulates the initiator protein of Vibrio cholerae chromosome II replication. Proc. Natl. Acad. Sci. USA 2008, 105, 10577-10582. [CrossRef] [PubMed]

9. Jha, J.K.; Ghirlando, R.; Chattoraj, D.K. Initiator protein dimerization plays a key role in replication control of Vibrio cholerae chromosome 2. Nucleic Acids Res. 2014, 42, 10538-10549. [CrossRef] [PubMed]

10. Orlova, N.; Gerding, M.; Ivashkiv, O.; Olinares, P.D.B.; Chait, B.T.; Waldor, M.K.; Jeruzalmi, D. The replication initiator of the cholera pathogen's second chromosome shows structural similarity to plasmid initiators. Nucleic Acids Res. 2017, 45, 3724-3737. [CrossRef] [PubMed] 
11. Jha, J.K.; Li, M.; Ghirlando, R.; Miller Jenkins, L.M.; Wlodawer, A.; Chattoraj, D. The DnaK chaperone uses different mechanisms to promote and inhibit replication of Vibrio cholerae chromosome 2. Mbio 2017, 8. [CrossRef] [PubMed]

12. Venkova-Canova, T.; Chattoraj, D.K. Transition from a plasmid to a chromosomal mode of replication entails additional regulators. Proc. Natl. Acad. Sci. USA 2011, 108, 6199-6204. [CrossRef] [PubMed]

13. Demarre, G.; Chattoraj, D.K. DNA adenine methylation is required to replicate both Vibrio cholerae chromosomes once per cell cycle. PLoS Genet. 2010, 6. [CrossRef] [PubMed]

14. Koch, B.; Ma, X.; Lobner-Olesen, A. Replication of Vibrio cholerae chromosome I in Escherichia coli: Dependence on dam methylation. J. Bacteriol. 2010, 192, 3903-3914. [CrossRef] [PubMed]

15. Egan, E.S.; Lobner-Olesen, A.; Waldor, M.K. Synchronous replication initiation of the two Vibrio cholerae chromosomes. Curr. Biol. 2004, 14, R501-R502. [CrossRef] [PubMed]

16. Chao, M.C.; Pritchard, J.R.; Zhang, Y.J.; Rubin, E.J.; Livny, J.; Davis, B.M.; Waldor, M.K. High-resolution definition of the Vibrio cholerae essential gene set with hidden Markov model-based analyses of transposon-insertion sequencing data. Nucleic Acids Res. 2013, 41, 9033-9048. [CrossRef] [PubMed]

17. Kamp, H.D.; Patimalla-Dipali, B.; Lazinski, D.W.; Wallace-Gadsden, F.; Camilli, A. Gene fitness landscapes of Vibrio cholerae at important stages of its life cycle. PLoS Pathog. 2013, 9. [CrossRef] [PubMed]

18. Jha, J.K.; Demarre, G.; Venkova-Canova, T.; Chattoraj, D.K. Replication regulation of Vibrio cholerae chromosome II involves initiator binding to the origin both as monomer and as dimer. Nucleic Acids Res. 2012, 40, 6026-6038. [CrossRef] [PubMed]

19. Gerding, M.A.; Chao, M.C.; Davis, B.M.; Waldor, M.K. Molecular dissection of the essential features of the origin of replication of the second Vibrio cholerae chromosome. Mbio 2015, 6. [CrossRef] [PubMed]

20. Baek, J.H.; Chattoraj, D.K. Chromosome I controls chromosome II replication in Vibrio cholerae. PLoS Genet. 2014, 10. [CrossRef] [PubMed]

21. Val, M.E.; Marbouty, M.; de Lemos Martins, F.; Kennedy, S.P.; Kemble, H.; Bland, M.J.; Possoz, C.; Koszul, R.; Skovgaard, O.; Mazel, D. A checkpoint control orchestrates the replication of the two chromosomes of Vibrio cholerae. Sci. Adv. 2016, 2. [CrossRef] [PubMed]

22. Rasmussen, T.; Jensen, R.B.; Skovgaard, O. The two chromosomes of Vibrio cholerae are initiated at different time points in the cell cycle. EMBO J. 2007, 26, 3124-3131. [CrossRef] [PubMed]

23. Stokke, C.; Waldminghaus, T.; Skarstad, K. Replication patterns and organization of replication forks in Vibrio cholerae. Microbiology 2011, 157, 695-708. [CrossRef] [PubMed]

24. Val, M.E.; Kennedy, S.P.; Soler-Bistue, A.J.; Barbe, V.; Bouchier, C.; Ducos-Galand, M.; Skovgaard, O.; Mazel, D. Fuse or die: How to survive the loss of Dam in Vibrio cholerae. Mol. Microbiol. 2014, 91, 665-678. [CrossRef] [PubMed]

25. Liang, X.; Baek, C.H.; Katzen, F. Escherichia coli with two linear chromosomes. ACS Synth. Biol. 2013, 2, 734-740. [CrossRef] [PubMed]

26. Skarstad, K.; Steen, H.B.; Boye, E. Cell cycle parameters of slowly growing Escherichia coli B/r studied by flow cytometry. J. Bacteriol. 1983, 154, 656-662. [PubMed]

27. Schindler, D.; Milbredt, S.; Sperlea, T.; Waldminghaus, T. Design and assembly of DNA sequence libraries for chromosomal insertion in bacteria based on a set of modified moclo vectors. ACS Synth. Biol. 2016, 5, 1362-1368. [CrossRef] [PubMed]

28. Simmons, L.A.; Breier, A.M.; Cozzarelli, N.R.; Kaguni, J.M. Hyperinitiation of DNA replication in Escherichia coli leads to replication fork collapse and inviability. Mol. Microbiol. 2004, 51, 349-358. [CrossRef] [PubMed]

29. Milbredt, S.; Farmani, N.; Sobetzko, P.; Waldminghaus, T. DNA Replication in engineered Escherichia coli genomes with extra replication origins. ACS Synth. Biol. 2016, 5, 1167-1176. [CrossRef] [PubMed]

30. Julio, S.M.; Heithoff, D.M.; Provenzano, D.; Klose, K.E.; Sinsheimer, R.L.; Low, D.A.; Mahan, M.J. DNA adenine methylase is essential for viability and plays a role in the pathogenesis of Yersinia pseudotuberculosis and Vibrio cholerae. Infect. Immun. 2001, 69, 7610-7615. [CrossRef] [PubMed]

31. Uhlin, B.E.; Nordstrom, K. Plasmid incompatibility and control of replication: Copy mutants of the R-factor R1 in Escherichia coli K-12. J. Bacteriol. 1975, 124, 641-649. [PubMed]

32. Carleton, S.; Projan, S.J.; Highlander, S.K.; Moghazeh, S.M.; Novick, R.P. Control of pT181 replication II. Mutational analysis. EMBO J. 1984, 3, 2407-2414. [PubMed] 
33. Messerschmidt, S.J.; Schindler, D.; Zumkeller, C.M.; Kemter, F.S.; Schallopp, N.; Waldminghaus, T. Optimization and characterization of the synthetic secondary chromosome synVicII in Escherichia coli. Front. Bioeng. Biotechnol. 2016, 4. [CrossRef] [PubMed]

34. Bates, D.B.; Asai, T.; Cao, Y.; Chambers, M.W.; Cadwell, G.W.; Boye, E.; Kogoma, T. The DnaA box R4 in the minimal oriC is dispensable for initiation of Escherichia coli chromosome replication. Nucleic Acids Res. 1995, 23, 3119-3125. [CrossRef] [PubMed]

35. Yamaichi, Y.; Duigou, S.; Shakhnovich, E.A.; Waldor, M.K. Targeting the replication initiator of the second Vibrio chromosome: Towards generation of vibrionaceae-specific antimicrobial agents. PLoS Pathog. 2009, 5. [CrossRef] [PubMed]

36. Val, M.E.; Skovgaard, O.; Ducos-Galand, M.; Bland, M.J.; Mazel, D. Genome engineering in Vibrio cholerae: A feasible approach to address biological issues. PLoS Genet. 2012, 8. [CrossRef] [PubMed]

37. Xie, G.; Johnson, S.L.; Davenport, K.W.; Rajavel, M.; Waldminghaus, T.; Detter, J.C.; Chain, P.S.; Sozhamannan, S. Exception to the rule: Genomic characterization of naturally occurring unusual Vibrio cholerae strains with a single chromosome. Int. J. Genom. 2017. [CrossRef] [PubMed]

38. Messerschmidt, S.J.; Kemter, F.S.; Schindler, D.; Waldminghaus, T. Synthetic secondary chromosomes in Escherichia coli based on the replication origin of chromosome II in Vibrio cholerae. Biotechnol. J. 2015, 10, 302-314. [CrossRef] [PubMed]

39. Fossum, S.; De Pascale, G.; Weigel, C.; Messer, W.; Donadio, S.; Skarstad, K. A robust screen for novel antibiotics: Specific knockout of the initiator of bacterial DNA replication. FEMS Microbiol. Lett. 2008, 281, 210-214. [CrossRef] [PubMed]

40. Lobner-Olesen, A.; Atlung, T.; Rasmussen, K.V. Stability and replication control of Escherichia coli minichromosomes. J. Bacteriol. 1987, 169, 2835-2842. [CrossRef] [PubMed]

41. Lobner-Olesen, A. Distribution of minichromosomes in individual Escherichia coli cells: Implications for replication control. EMBO J. 1999, 18, 1712-1721. [CrossRef] [PubMed]

42. Skarstad, K.; Lobner-Olesen, A. Stable co-existence of separate replicons in Escherichia coli is dependent on once-per-cell-cycle initiation. EMBO J. 2003, 22, 140-150. [CrossRef] [PubMed]

43. Richardson, T.T.; Harran, O.; Murray, H. The bacterial DnaA-trio replication origin element specifies single-stranded DNA initiator binding. Nature 2016, 534, 412-416. [CrossRef] [PubMed]

44. Camara, J.E.; Breier, A.M.; Brendler, T.; Austin, S.; Cozzarelli, N.R.; Crooke, E. Hda inactivation of DnaA is the predominant mechanism preventing hyperinitiation of Escherichia coli DNA replication. EMBO Rep. 2005, 6, 736-741. [CrossRef] [PubMed]

45. Simmons, L.A.; Kaguni, J.M. The DnaAcos allele of Escherichia coli: Hyperactive initiation is caused by substitution of A184V and $\mathrm{Y} 271 \mathrm{H}$, resulting in defective ATP binding and aberrant DNA replication control. Mol. Microbiol. 2003, 47, 755-765. [CrossRef] [PubMed]

46. Yamaguchi, K.; Tomizawa, J. Establishment of Escherichia coli cells with an integrated high copy number plasmid. Mol. Gen. Genet. 1980, 178, 525-533. [CrossRef] [PubMed]

47. Hansen, E.B.; Yarmolinsky, M.B. Host participation in plasmid maintenance: Dependence upon $d n a A$ of replicons derived from P1 and F. Proc. Natl. Acad. Sci. USA 1986, 83, 4423-4427. [CrossRef] [PubMed]

48. Waldminghaus, T.; Skarstad, K. The Escherichia coli SeqA protein. Plasmid 2009, 61, 141-150. [CrossRef] [PubMed]

49. Saint-Dic, D.; Kehrl, J.; Frushour, B.; Kahng, L.S. Excess SeqA leads to replication arrest and a cell division defect in Vibrio cholerae. J. Bacteriol. 2008, 190, 5870-5878. [CrossRef] [PubMed]

50. McGarry, K.C.; Ryan, V.T.; Grimwade, J.E.; Leonard, A.C. Two discriminatory binding sites in the Escherichia coli replication origin are required for DNA strand opening by initiator DnaA-ATP. Proc. Natl. Acad. Sci. USA 2004, 101, 2811-2816. [CrossRef] [PubMed]

51. Venkova-Canova, T.; Baek, J.H.; Fitzgerald, P.C.; Blokesch, M.; Chattoraj, D.K. Evidence for two different regulatory mechanisms linking replication and segregation of Vibrio cholerae chromosome II. PLoS Genet. 2013, 9. [CrossRef] [PubMed]

52. Miller, J.H. A Short Course in Bacterial Genetics: A Laboratory Manual and Handbook for Escherichia coli and Related Bacteria; Cold Spring Harbor Laboratory Press: Cold Spring Harbor, NY, USA, 1992.

53. Johnsen, L.; Flatten, I.; Morigen; Dalhus, B.; Bjoras, M.; Waldminghaus, T.; Skarstad, K. The G157C mutation in the Escherichia coli sliding clamp specifically affects initiation of replication. Mol. Microbiol. 2011, 79, 433-446. [CrossRef] [PubMed] 
54. Boye, E.; Lobner-Olesen, A.; Skarstad, K. Timing of chromosomal replication in Escherichia coli. Biochim. Biophys. Acta 1988, 951, 359-364. [CrossRef]

55. Waldminghaus, T.; Weigel, C.; Skarstad, K. Replication fork movement and methylation govern SeqA binding to the Escherichia coli chromosome. Nucleic Acids Res. 2012, 40, 5465-5476. [CrossRef] [PubMed]

56. Jiang, C.; Brown, P.J.; Ducret, A.; Brun, Y.V. Sequential evolution of bacterial morphology by co-option of a developmental regulator. Nature 2014, 506, 489-493. [CrossRef] [PubMed]

57. Gibson, D.G.; Young, L.; Chuang, R.Y.; Venter, J.C.; Hutchison, C.A., III; Smith, H.O. Enzymatic assembly of DNA molecules up to several hundred kilobases. Nat. Methods 2009, 6, 343-345. [CrossRef] [PubMed]

58. Weber, E.; Engler, C.; Gruetzner, R.; Werner, S.; Marillonnet, S. A modular cloning system for standardized assembly of multigene constructs. PLoS ONE 2011, 6. [CrossRef] [PubMed]

59. Miller, V.L.; Mekalanos, J.J. A novel suicide vector and its use in construction of insertion mutations: Osmoregulation of outer membrane proteins and virulence determinants in Vibrio cholerae requires toxR. J. Bacteriol. 1988, 170, 2575-2583. [CrossRef] [PubMed]

60. Cherepanov, P.P.; Wackernagel, W. Gene disruption in Escherichia coli: TcR and KmR cassettes with the option of Flp-catalyzed excision of the antibiotic-resistance determinant. Gene 1995, 158, 9-14. [CrossRef]

(C) 2017 by the authors. Licensee MDPI, Basel, Switzerland. This article is an open access article distributed under the terms and conditions of the Creative Commons Attribution (CC BY) license (http://creativecommons.org/licenses/by/4.0/). 